\title{
Chemical Hazard Assessment and Prioritization (CHAP): An Intuitive Excel Tool
}

\section{PURPOSE}

The purpose of CHAP is to assist small to medium workplaces and their Joint Health and Safety Committees to:

1. Better understand the hazards associated with the chemicals/products they are using; and

2. Prioritize the most 'hazardous' chemicals/products for additional assessment of the effectiveness of control measures which are currently in-place.

\section{HOW DOES IT DO THIS?}

One way of assessing and ranking chemical hazards is through 'hazard banding'. In this approach, the hazards associated with a chemical are allocated to different 'hazard bands'. For example, a chemical assigned an " $A$ " 'hazard band' is a 'low' hazard, up to an "E" 'hazard band', which is an 'extremely high' hazard. By looking at what 'hazard band' a chemical is allocated to, you are able to determine how hazardous the chemical is. This CHAP tool allows you to use information from Safety Data Sheets to determine the hazard bands of the chemicals you use.

\section{EXCEL?}

Originally, to assess your chemicals, you would have to put them on many papers and score them manually. This Excel tool integrates all the data and uses macros to engineer the tool so that this task is done much more quickly and is more easily managed. Soon, this tool will be available for anyone to use.

Some key features:

\begin{tabular}{|l|l|}
\hline $\begin{array}{l}\text { AUTOMATIC } \\
\begin{array}{l}\text { fills out data for you, } \\
\text { - Search functions }\end{array}\end{array}$ & $\begin{array}{l}\text { INTEGRATED } \\
\text { - Export key data to Word } \\
\text { On Excel - a software on many } \\
\text { work computers }\end{array}$ \\
\hline $\begin{array}{l}\text { EXPANDS WITH YOU } \\
\text { - Assess as many as chemicals } \\
\text { you want, as your chemical } \\
\text { inventory expands }\end{array}$ & $\begin{array}{l}\text { M IN IMIZES ERRORS } \\
\text { - Removes redundant data }\end{array}$ \\
\hline
\end{tabular}

